\title{
Further Studies on the Antigens of Paramecium aurelia with the Aid of Fluorescent Antibodies
}

\author{
By G. H. BEALE AND M. R. MOTT \\ Department of Animal Genetics, University of Edinburgh
}

(Received 6 November 1961)

\begin{abstract}
SUMMARY
A technique for sectioning fixed preparations of Paramecium aurelia suitable for subsequent treatment with fluorescent antisera is described. Following application of specific fluorescein and rhodamine conjugates of paramecium antisera to sectioned paramecia, fluorescence was observed both on the surface structures (pellicle and cilia) and in the cytoplasm, but not in the macronucleus. Fluorescence of the cytoplasm was prevented by pretreating the sections with non-homologous, non-fluorescent antiserum. It was concluded that the immobilizing antigens were substances covering only the pellicle and cilia, and that the internal cytoplasmic antigens were relatively invariant in paramecia of diverse immobilization antigen type. Study of transforming organisms showed that new antigen appeared first on the pellicle, and later on the cilia. All the cilia of a given cell bore the same antigen or mixtures of antigen.
\end{abstract}

\section{INTRODUCTION}

In a previous paper (Beale \& Kacser, 1957) the effect of treating whole paramecia, both living and fixed, with fluorescein-conjugated antisera was described. The immobilization antigens were then shown to be localized on the surface structures, but the presence or absence of antigens in the interior of the cells could not be established with certainty owing to the possibility that the antibodies had failed to penetrate through the external membranes of the intact organisms. In the present study we describe experiments involving the treatment of sectioned paramecia, whose internal contents are presumably as accessible to applied antisera as the surface structures. We have also now made use of the technique of double staining with both fluorescein and rhodamine conjugates in order to detect the presence of two different antigens in a single preparation and to follow the process of transformation from one antigenic type to another.

\section{METHODS}

Culture media. The paramecia were grown in dried grass or lettuce infusions containing Aerobacter aerogenes. As a non-nutrient medium for washing the organisms the following solution (which will be referred to as solution MS) was used: $0.013 \mathrm{M}-\mathrm{NaCl}, 0.0003 \mathrm{M}-\mathrm{KCl}, 0.003 \mathrm{M}-\mathrm{CaCl}_{2}$ buffered to $\mathrm{pH} 7$ with $0.004 \mathrm{M}$ phosphate. For general methods used in the cultivation of paramecia, see Sonneborn (1950).

Stocks and serotypes of Paramecium aurelia. Stock 168 (variety/syngen 1), 
serotypes $\mathrm{G}$ and $\mathrm{D}$ were used. For testing the specificity of the effect of fluorescent solutions, pairs of conjugating paramecia were prepared, one member of each pair being antigenic type $168 \mathrm{G}$, the other type $168 \mathrm{D}$. Type $168 \mathrm{G}$ is stable at $25^{\circ}$, type $168 \mathrm{D}$ at temperatures above $30^{\circ}$. To get rapid transformation from $168 \mathrm{G}$ to $168 \mathrm{D}$, about $100 \mathrm{ml}$. of a culture of $168 \mathrm{G}$ were placed in a 2 l. flask and $300 \mathrm{ml}$. of culture medium (preheated to $35^{\circ}$ ) added. The culture was then incubated at $35^{\circ}$ and after about $18 \mathrm{hr}$. nearly all the organisms had completed the transformation to type $168 \mathrm{D}$.

Preparation of fluorescent serum-conjugates. The antisera were prepared by injecting into rabbits homogenates of whole paramecia, as previously described (Sonneborn, 1950). Conjugation of antisera with fluorescein was at first done by the original method of Coons \& Kaplan (1950), later by the modified method of Marshall, Eveland \& Smith (1958). Whole sera were used. After conjugation, free dye was removed by passage through a column of De-acidite 'F.F.', buffered to $\mathrm{pH} 7$. The solution was finally dialysed against solution MS to give a final serum dilution of 1/8. This method resulted in a diminution of titre of immobilizing antibody to half the original value, after allowing for dilution.

Conjugation with rhodamine was effected as described by Chadwick, McEntegart $\&$ Nairn (1958). Initially whole serum was used but since the resultant preparation gave poor fluorescence, in later work the globulins were precipitated with $40 \%$ ammonium sulphate after conjugation with rhodamine. The precipitated rhodaminelabelled globulins were redissolved in a small volume of solution MS, dialysed against distilled water and solution MS, and finally passed through a column of De-acidite to remove any remaining free rhodamine. The volume was finally adjusted with solution MS to be the same as the original. Loss of antibody titre was again about one-half.

Fixation and sectioning of paramecia. The organisms were concentrated by gentle centrifugation, fixed in $1 \%$ osmic acid in solution MS for 20 min., washed five times in solution MS, and briefly spun down. About $1 \mathrm{ml}$. of a solution of gelatin dissolved in solution MS was added to the washed pellet; the gelatin solution was prepared by autoclaving a $7 \%(\mathrm{w} / \mathrm{v})$ solution at $25 \mathrm{lb}$. pressure for $20 \mathrm{~min}$. This resulted in partial hydrolysis of the gelatin and gave a solution of barely liquid consistency at $20^{\circ}$. The suspension of paramecia in gelatin was transferred with a pipette to a small plastic tube $\left(5 \times \frac{1}{2} \mathrm{~cm}\right.$.). The PVC ink sacs of Parker pens were found to be excellent for this purpose. After being filled, the sac was placed in a freezing cabinet at $-20^{\circ}$ with occasional gentle shaking to prevent the paramecia from sinking to the bottom before the contents were solidified. The frozen block was mounted on the chuck of a microtome in a freezing cabinet, the plastic sac stripped off with a razor and the gelatin block trimmed square. The block was sectioned at about $10 \mu$ thickness at a temperature of $-8^{\circ}$. The sections were individually unrolled on the knife and transferred to an albuminized slide with a camel hair brush. The sections, after being gently pressed flat on the slide, were left overnight in the freezing cabinet at $-8^{\circ}$.

Staining with fluorescent antibody conjugates. The slides were removed from the freezing cabinet and slightly warmed, causing the gelatin to melt and the sections to become well stuck to the slides. Staining and washing was done by carefully pipetting the various solutions on to the slides. The following treatments were 
used: (1) treatment with fluorescein conjugate alone, dilution $1 / 32$, for $2 \mathrm{hr}$. in the cold; (2) treatment with rhodamine conjugate alone, full strength, for $3 \mathrm{hr}$. in the cold; (3) double staining, first with fluorescein, then rhodamine; (4) any of the above, preceded by treatment with non-fluorescent, non-homologous serum (anti$192 \mathrm{X}$ ), dilution $1 / 2$, overnight in cold.

After each staining, the slides were washed in solution MS and finally a coverslip was placed on top and ringed with petroleum jelly to prevent evaporation. Fresh mounts gave the best results, but the preparations did not fade for several weeks or even months when kept in the cold and dark.

Fluorescence microscopy. The sections were examined by observing fluorescence under ultraviolet (u.v.) radiation, with a dark ground condenser on the microscope as described previously (Beale \& Kacser, 1957). For the greatest magnification $(\times 800)$ a special (Zeiss) oil-immersion objective with iris diaphragm was used. Under the conditions adopted, material treated with fluorescein-conjugate fluoresced much more brightly than material treated with rhodamine-conjugate.

Colour photography. High speed ektachrome film ASA 160 was used with exposures of 20 min. or longer. Great difficulty was experienced in getting adequate reproduction of the orange colour of rhodamine, especially in combination with fluorescein.

\section{RESULTS}

\section{Localization of antigens}

Sections of paramecia when treated with fluorescein or rhodamine conjugates of homologous antisera fluoresced brightly around the pellicle and cilia. This is illustrated in Pl. 1, fig. 1, showing a section through a pair of mating organisms $(168 \mathrm{G} \times 168 \mathrm{D})$, treated with fluorescein-conjugated $168 \mathrm{G}$ antiserum. It was found, however, that the cytoplasm of both homologous $(168 \mathrm{G})$ and non-homologous $(168 \mathrm{D})$ organisms fluoresced in these preparations. The region of the macronucleus was dark. The fluorescence of the cytoplasm was removed by pre-treating the sections with a nonhomologous non-fluorescent serum (anti-192X), as shown in Pl. 1, fig. 2. Such pretreatment also improved the specificity of the staining of the surface structures, for when very strong fluorescein-conjugated antisera were applied (in the absence of pretreatment), a faint green fluorescence appeared on sections of non-homologous organisms. The pretreatment eliminated this, leaving only a ghostly bluish 'autofluorescence' around the rim of the non-homologous organism (as seen in Pl. 1, fig. 2).

Double staining of mating pairs of paramecia $(168 \mathrm{G} \times 168 \mathrm{D})$ with fluoresceinconjugated $168 \mathrm{G}$ antiserum and rhodamine-conjugated $168 \mathrm{D}$ antiserum, preceded by treatment with non-fluorescent $192 \mathrm{X}$ antiserum, gave preparations showing one member of each pair with green pellicle and cilia, the other with orange pellicle and cilia (Pl. 1, fig. 3). In some pairs it was noticeable that the fluorescence characteristic of one mate extended for a short distance over the other. This was especially marked with the brighter green fluorescence of fluorescein.

These results, in addition to confirming the surface localization of the immobilization antigens, as discussed below, were of value in showing the specificity of the staining procedure, and the feasibility of double-staining of paramecium preparations containing two different antigens in the same cell. 


\section{Transformation experiments}

The double-staining technique was then used to study the appearance of a new antigen in organisms in the process of transforming from serotype $168 \mathrm{G}$ to type 168D. A culture of type $168 \mathrm{G}$ was placed at a high temperature, as described in Methods, and at intervals during the process of transformation to $168 \mathrm{D}$ samples were taken. Part of each sample was fixed, sectioned and treated successively with $168 \mathrm{G}$ fluorescein-conjugated antiserum and $168 \mathrm{D}$ rhodamine-conjugated antiserum. In addition parts of some samples were treated with fluorescein only or rhodamine only. Finally, live organisms from each sample were treated with unconjugated $168 \mathrm{G}$ antiserum and others with unconjugated $168 \mathrm{D}$ antiserum, and the immobilizing effect, when present, noted. These results are summarized in Table 1. It should be stated, however, that as there is some variation in the times for individual organisms to reach a given stage in the transformation process, the times given in Table 1 apply only to an average of the organisms in a given sample.

Table 1. Stages during transformation of Paramecium aurelia from antigenic type $168 \mathrm{G}$ to type $168 \mathrm{D}$ by growth at $3^{\circ}$

Effect of antisera (dil. 1/50) on live organisms

\begin{tabular}{|c|c|c|c|c|c|c|c|}
\hline \multirow[b]{3}{*}{ Stage } & \multirow{3}{*}{$\begin{array}{l}\text { Time of } \\
\text { growth } \\
\text { at } 35^{\circ} \\
\text { (hr.) }\end{array}$} & \multicolumn{2}{|c|}{$168 \mathrm{G}$ antiserum } & \multicolumn{2}{|c|}{$168 \mathrm{D}$ antiserum } & \multirow{2}{*}{\multicolumn{2}{|c|}{$\begin{array}{c}\text { Fluorescence following treatmen } \\
\text { with antibody conjugates } \\
\text { (green, } 168 \mathrm{G} \text {; orange, } 168 \mathrm{D} \text { ) }\end{array}$}} \\
\hline & & \multirow{2}{*}{$\begin{array}{l}\text { Immobilization } \\
\text { time } \\
\text { (min.) }\end{array}$} & \multirow{2}{*}{$\begin{array}{l}\text { Effect } \\
\text { after } \\
\mathbf{2 4} \mathrm{hr} . \\
\text { at } 20^{\circ}\end{array}$} & \multirow{2}{*}{$\begin{array}{c}\text { Inmobilization } \\
\text { time } \\
\text { (min.) }\end{array}$} & \multirow{2}{*}{$\begin{array}{l}\text { Effect } \\
\text { after } \\
\mathbf{2 4} \mathrm{hr} . \\
\text { at } 20^{\circ}\end{array}$} & & \\
\hline & & & & & & Pellicle & Cilia \\
\hline 1 & $0-2$ & 3 & \multirow{3}{*}{ Dead } & Unaffected & \multirow{3}{*}{ Alive } & Green & Green \\
\hline $\mathbf{2}$ & $2-3$ & 3 & & & & $\begin{array}{l}\text { Green ( + slight } \\
\text { orange) }\end{array}$ & Green \\
\hline $\mathbf{3}$ & 7 & 4 & & $\mathbf{R}$ & & $\begin{array}{l}\text { Orange }(+ \text { slight } \\
\text { green }\end{array}$ & Green \\
\hline$*$ & \multicolumn{5}{|c|}{$\rightarrow------------\cdots--$} & ------ & $-----\cdot$ \\
\hline 4 & 8 & 6 & & $\mathbf{R}$ & & Mainly orange & $\begin{array}{l}\text { Green (+ slight } \\
\text { orange) }\end{array}$ \\
\hline $\mathbf{5}$ & 11 & 35 & & 45 & & Orange & Green and oras \\
\hline 6 & 12 & $\mathbf{R}$ & Alive & 20 & Dead & Orange & Mainly orange \\
\hline 2 & $13-16$ & $\mathbf{R}$ & & $\mathbf{3}$ & & Orange & $\begin{array}{l}\text { Orange ( } \\
\text { green) }\end{array}$ \\
\hline $\mathbf{3}$ & $18-20$ & Unaffected & & 3 & & Orange & Orange \\
\hline
\end{tabular}

It was found that the organisms passed through a series of intermediate stages showing increasing amounts of 'new' antigen (168D) and decreasing amounts of the old $(168 \mathrm{G})$, in individual paramecia. It is of interest to note that at stage 3 , after $7 \mathrm{hr}$. at $35^{\circ}$, the living organisms were capable of being immobilized by $168 \mathrm{G}$ antiserum almost as rapidly as at the start, and were only slightly affected by $168 \mathrm{D}$ antiserum. This is consistent with the finding from the fluorescence examination that the cilia still contained antigen $168 \mathrm{G}$. At the same stage, however, the pellicle contained predominantly antigen $168 \mathrm{D}$. Thus it is clear that production of 'new' antigen took place first on the pellicle and only later spread to the cilia. 
It was also noted that at stage $4(8 \mathrm{hr}$.) the cilia still contained such a high proportion of antigen $168 \mathrm{G}$ that the paramecia were immobilized by $168 \mathrm{G}$ antiserum in a relatively short time $(6 \mathrm{~min}$.), but after a further $24 \mathrm{hr}$. at room temperature in presence of $168 \mathrm{G}$ antiserum the same organisms had recovered. Here the process of transformation continued after the paramecia had been immobilized by $168 \mathrm{G}$ antiserum. We presume that the $168 \mathrm{G}$-type antigen-antibody complex on the tips of the cilia was eventually shed and replaced by $168 \mathrm{D}$ antigen. This is in conformity with the finding described elsewhere (Beale, 1958) that paramecia which have already begun the transformation process carry it through to completion, even though the conditions (in that case a lower temperature) may not favour maintenance of the new serotype (168D).

At intermediate stages when both antigens were present in a single organism, the pellicle was uniform, as regards fluorescence, at different points of the organism; the same applied to the cilia. By careful comparisons of preparations treated with single and double stains, and with observations of a given organism both in u.v. radiation and in visible light, it was possible to establish that a single cilium sometimes contained both antigens. There was no evidence supporting the view that new cilia which developed bore the new antigen and the old cilia bore the old antigen.

\section{DISCUSSION}

The present results show that the immobilization antigens of paramecia are localized on the pellicle and cilia only. Other antigens are present within the organisms, as shown by Preer \& Preer (1959) by gel diffusion studies with isolated cellular components. Since our antisera were prepared by injection into rabbits of homogenates derived from whole paramecia, antibodies against the internal antigens would be present in the fluorescent antisera used in the present experiments. Hence treatment of sections by such sera resulted in fluorescence in the cytoplasm as well as on the surface structures. The fact that in our earlier studies (Beale \& Kacser, 1957) treatment of intact paramecia with fluorescent antisera did not result in any internal fluorescence means that the antibodies had not penetrated through the outer membranes of intact paramecia.

The effect of pre-treatment with non-homologous (192X) antiserum in preventing the internal fluorescence from appearing is interpreted to mean that the internal (cytoplasmic) antigens are relatively invariant in paramecia which bear different immobilization antigens. Hence the $192 \mathrm{X}$ antiserum contained antibodies which neutralized the internal antigens of types $168 \mathrm{G}$ and $168 \mathrm{D}$, while leaving the immobilization antigens unaffected and able to react subsequently with specific (fluorescent) immobilization antibodies.

The improvement in specificity of the reactions even of the surface structures with fluorescent antisera consequent upon pretreatment with non-homologous antiserum indicates that even the surface structures contained some antigen other than the specific immobilization ones. This effect is, however, relatively slight: only with very concentrated fluorescent antisera was there appreciable staining of the surfaces of non-homologous organisms.

The behaviour of the organisms during antigen transformation indicates that there is a central control of synthesis of antigen over the whole surface. From the 
initial appearance of new antigen on the pellicle, it is reasonable to assume that this synthesis occurs there, and that there is a secondary spread of antigen over the cilia. From earlier genetic work (see Beale, 1954, 1957) it is known that the specificity of the immobilization antigens is controlled by certain genes, but that the control in expression of these genes is exercised by cytoplasmic factors. These are the factors which control the development of a particular kind of antigen over the whole surface of the paramecium. It now appears that such cytoplasmic factors cannot be, as once suggested (Beale, 1948), the immobilization antigens themselves, for there is no evidence that the immobilization antigens occur in the cytoplasm. It is therefore now important to try to establish the nature of these cytoplasmic factors. Presumably they consist of some substance or complex occupying a position intermediate between the antigen-determining genes and their products the immobilization antigens, which are now known to be proteins (Preer, 1959; Bishop, 1961). Future work will be directed towards identifying these cytoplasmic factors.

We thank Dr H. Kacser for much help in the earlier stages of this work, Dr R. Alexander for supplying samples of fluorescein and rhodamine preparations, Dr I. Tallan for making preliminary trials of the technique of pretreatment with non-homologous antiserum, and the Parker Pen Co. for kindly supplying the plastic ink sacs. The work was supported by grants from the Medical Research Council for scientific assistance, and from the Royal Society for apparatus.

\section{REFERENCES}

Beale, G. H. (1948). The process of transformation of antigenic type in Paramecium aurelia, variety 4. Proc. nat. Acad. Sci., Wash. 34, 418.

Beale, G. H. (1954). The Genetics of Paramecium aurelia. Cambridge University Press.

BEALE, G. H. (1957). The antigen system of Paramecium aurelia. Int. Rev. Cytol. 6, 1.

Beale, G. H. (1958). The role of the cytoplasm in antigen determination in Paramecium aurelia. Proc. roy. Soc. B, 148, 308.

Beale, G. H. \& Kacser, H. (1957). Studies on the antigens of Paramecium aurelia with the aid of fluorescent antibodies. J. gen. Microbiol. 17, 68.

Bishop, J. (1961). Purification of an immobilization antigen of Paramecium aurelia, variety 1. Biochim. biophys. Acta, 50, 471.

Chadwick, C. S., McEntegart, M. G. \& Nairn, R. C. (1958). Fluorescent protein tracers: a trial of new fluorochromes and the development of an alternative to fluorescein. Immunology, $1,315$.

Coons, A. H. \& KAPLAN, M. H. (1950). Localization of antigen in tissue cells. II. Improvements in a method for the detection of antigen by means of fluorescent antibody. J. exp. Med. 91, 1.

Marshall, J. M., Eveland, W. C. \& Smith, C. W. (1958). Superiority of fluorescein isothiocyanate (Riggs) for fluorescent antibody technic with a modification of the application. Proc. Soc. exp. Biol., N.Y. 98, 898.

Preer, J. (1959). Studies on the immobilization antigens of Paramecium. III. Properties. J. Immunol. 83, 385.

Preer, J. R. \& Preer, L. B. (1959). Gel diffusion studies on the antigens of isolated cellular components of Paramecium. J. Protozool. 6, 88.

Sonneborn, T. M. (1950). Methods in the general biology and genetics of Paramecium aurelia. J. exp. Zool. 113, 87. 


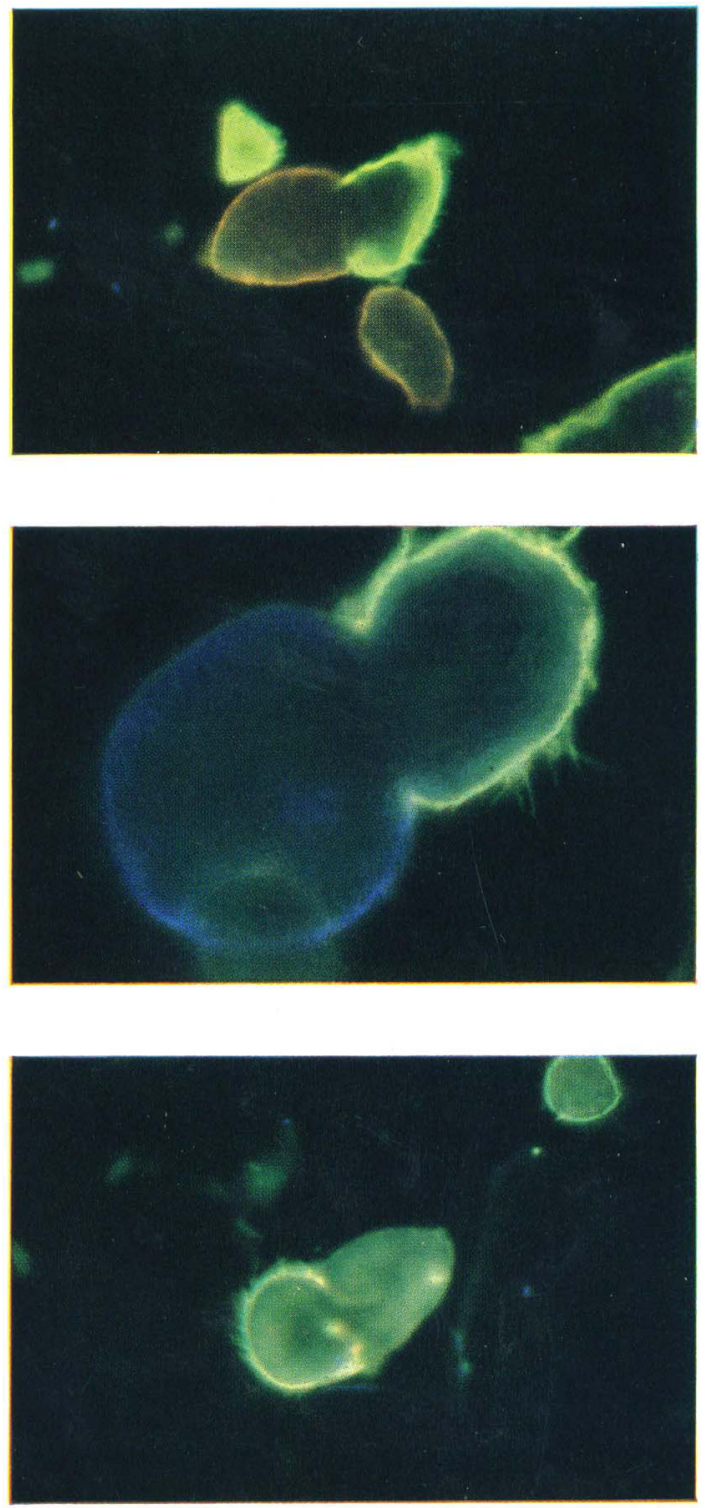


\section{EXPLANATION OF PLATE 1}

Fig. 1. Section through conjugating pair of paramecia, antigenic types $168 \mathrm{G}$ and $168 \mathrm{D}$, treated with fluorescein-conjugated $168 \mathrm{G}$ antiserum. Note fluorescent pellicle and cilia on conjugant at left (presumed $168 \mathrm{G}$ ), and fluorescent cytoplasm in both conjugants. $\times 128$.

Fig. 2. As Fig. 1, but pretreated with non-fluorescent $192 \mathrm{X}$ antiserum to prevent reaction of cytoplasmic antigens with fluorescent antibody. Only the immobilization antigen, on pellicle and cilia of $168 \mathrm{G}$ cell, now shows the green fluorescence of fluorescein. $\times 320$.

Fig. 3. Section through pair of conjugants $168 \mathrm{G}$ and $168 \mathrm{D}$, pre-treated with non-fluorescent $192 \mathrm{X}$ antiserum, then with fluorescein-conjugated $168 \mathrm{G}$ antiserum and finally rhodamineconjugated $168 \mathrm{D}$ antiserum. $\times 128$. 
